\title{
Microstructure and magnetic properties of the $(\mathrm{FePt})_{100-x} \mathrm{Cr}_{x}$ thin films
}

\author{
P. C. Kuo \\ Institute of Materials Science and Engineering, National Taiwan University, Taipei 107, Taiwan \\ Y. D. Yao ${ }^{\mathrm{a}}$ \\ Institute of Physics, Academia Sinica, Taipei 115, Taiwan \\ C. M. Kuo and H. C. Wu \\ Institute of Materials Science and Engineering, National Taiwan University, Taipei 107, Taiwan
}

\begin{abstract}
The $(\mathrm{FePt})_{100-x} \mathrm{Cr}_{x}$ alloy thin films with $x=0-16$ at. \% were fabricated on natural-oxidized $\mathrm{Si}(111)$ substrate by dc magnetron sputtering. The as-deposited films were annealed between 300 and $750{ }^{\circ} \mathrm{C}$ in order to transform the soft magnetic fcc $\gamma$-FePt phase to the hard magnetic fct $\gamma_{1}-\mathrm{FePt}$ phase. The addition of $\mathrm{Cr}$ in the FePt thin films will reduce its saturation magnetization and coercivity, however, it could inhibit the grain growth during annealing of the samples. The optimum condition for high-density magnetic recording purpose of the $(\mathrm{FePt})_{100-x} \mathrm{Cr}_{x}$ alloy films was found with $x=5$ at. $\%$, annealing at $650{ }^{\circ} \mathrm{C}$ for $15 \mathrm{~min}$, and ice water quench cooling. According to the transmission electron microscopy study, the average grain size in the annealed $(\mathrm{FePt})_{100-x} \mathrm{Cr}_{x}$ alloy thin films decrease from 60 to $5 \mathrm{~nm}$ with increasing $x$ from 0 to 16. (C) 2000 American Institute of Physics. [S0021-8979(00)52408-6]
\end{abstract}

\section{INTRODUCTION}

In recent years, the FePt thin films have received significant attention owing to their potential applications in magnetic and magneto-optic recording. ${ }^{1-4}$ In the thin film recording media, high coercivity and small grain size are required for high-density longitudinal magnetic recording. The ordered equiatomic FePt phase with tetragonal $\mathrm{L}_{0}$ structure has very high magnetocrystalline anisotropy constant $\left(K_{u}\right.$ $\sim 7 \times 10^{7} \mathrm{ergs} / \mathrm{cm}^{3}$, high coercivity, good corrosion resistance, and large energy products $(B H)_{\max } \cdot{ }^{5-8}$ It suits for the application in magnetic recording media and various micromagnetic devices. Previous investigations have shown that the magnetic properties of the FePt films are sensitive to process parameters. ${ }^{9,10}$ In this work, the effects of annealing temperature and doping concentration of $\mathrm{Cr}$ on the magnetic properties and grain size of the FePt thin film were investigated.

\section{EXPERIMENT}

The $(\mathrm{FePt})_{100-x} \mathrm{Cr}_{x}$ alloy thin films with $x$ $=0-16$ at. $\%$ were fabricated on natural-oxidized $\mathrm{Si}(111)$ substrate by dc magnetron sputtering. A mosaic target consisting of high purity iron disk $(99.99 \%)$ overlaid with high purity platinum pieces $(99.99 \%)$ was used. Two separated dc magnetron guns were used for Co sputtering FePt and $\mathrm{Cr}$, respectively. The deposition rate is about $0.6 \AA / s$. The base pressure in the vacuum system was under $5 \times 10^{-7}$ Torr, and after the high purity argon gas $(99.9995 \%)$ was introduced, the sputter pressure of 5 mTorr was used in this study. The $\left(\mathrm{Fe}_{50} \mathrm{Pt}_{50}\right)_{100-x} \mathrm{Cr}_{x}$ film thickness was fixed at $10 \mathrm{~nm}$ in order to examine the possibility of applying these films in highdensity magnetic recording media. The as-deposited film was sealed in a quartz capsule and then postannealed in vacuum

${ }^{a)}$ Electronic mail: phyao@gate.sinica.edu.tw at a temperature between 300 and $750{ }^{\circ} \mathrm{C}$. The annealing time was $15 \mathrm{~min}$, and the film was quenched in ice water after annealing.

The magnetic properties of the film at room temperature were measured with a superconducting quantum interface device (SQUID). Microstructure of the film was characterized by $\mathrm{x}$-ray diffractometer. The average grain size of the film was measured by the transmission electron microscopy (TEM) bright-field image. Composition and homogeneity of the film were determined by energy disperse spectrum (EDS).

\section{RESULTS AND DISCUSSION}

The structure and magnetic properties of the pure FePt films have been reported before. ${ }^{9,10}$ In this investigation, the influence of $\mathrm{Cr}$ addition on the structure and magnetic properties of the FePt thin films is reported. The addition of $\mathrm{Cr}$ in the FePt thin films from 0 to 16 at. \% reduces its saturation magnetization roughly from 700 to $400 \mathrm{emu} / \mathrm{cm}^{3}$, and its coercivity roughly from 10 to $4 \mathrm{kOe}$. From the x-ray diffraction pattern studied, we find that all as-deposited (FePt ${ }_{100-x} \mathrm{Cr}_{x}$ alloy thin films with $x=0-16$ at. $\%$ are polycrystalline fcc $\gamma$-phase structure. The $\gamma$-FePt phase is magnetically soft in bulk form, however, due to the contribution of large internal stresses introduced by sputtering process, it has higher coercivity in the thin film form than in the bulk form. These internal stresses may produce some microcracks in the as-deposited FePt film for thicker films (e.g., 200 $\mathrm{nm}) .{ }^{1,9}$ However, we found that these microcracks disappeared for the $10 \mathrm{~nm}$ film. It indicates that the internal stress of the film was decreased as film thickness decreased.

For annealed films, small amount of $\mathrm{FeCr}$ phase was observed for all the doped films; and the fct $\gamma_{1}$-FePt phase is dominated for samples with annealing temperature roughly above $500^{\circ} \mathrm{C}$. As an example, Fig. 1 shows the x-ray diffrac- 


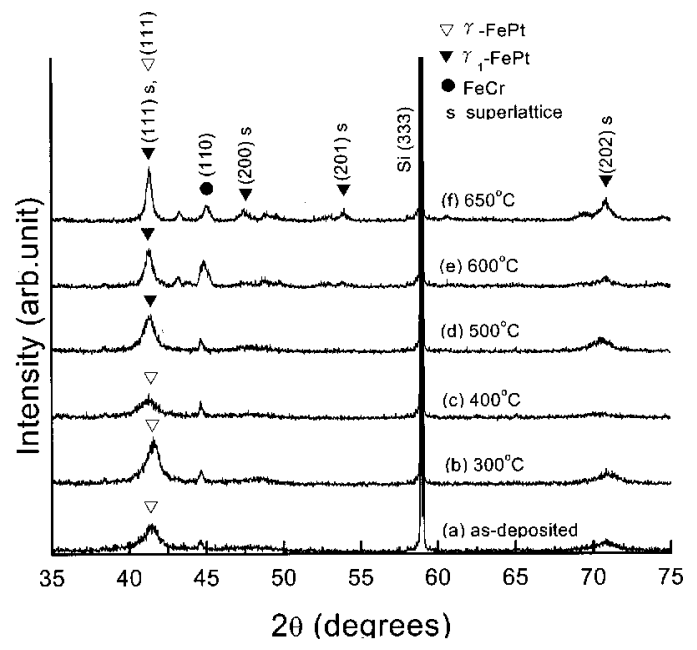

FIG. 1. X-ray diffraction patterns of the $(\mathrm{FePt})_{88} \mathrm{Cr}_{12}$ alloy thin films with (a) as-deposited, and annealed at (b) 300, (c) 400, (d) 500, (e) 600, and (f) $650{ }^{\circ} \mathrm{C}$ for $15 \mathrm{~min}$.

tion patterns of the $(\mathrm{FePt})_{88} \mathrm{Cr}_{12}$ thin films with (a) asdeposited and (b) to (f) annealed between 300 and $650^{\circ} \mathrm{C}$ for $15 \mathrm{~min}$. It is clear that the fcc $\gamma$-FePt phase is dominated in the as-deposited films and the fct $\gamma_{1}$-FePt phase increases with increasing the annealing temperature. For the two films annealed at the highest temperatures, there are a few unidentified lines in the $\mathrm{x}$-ray spectra. It may be due to the reaction of the films with their substrates during high temperature annealing. Figure 2 is a typical TEM bright-field image and diffraction pattern of a $\left(\mathrm{Fe}_{50} \mathrm{Pt}_{50}\right)_{95} \mathrm{Cr}_{5}$ film annealed at $650{ }^{\circ} \mathrm{C}$ for $15 \mathrm{~min}$. It shows that the average grain size is roughly $12 \mathrm{~nm}$. The fcc $\gamma$-FePt, fct $\gamma_{1}-\mathrm{FePt}$, and FeCr phases

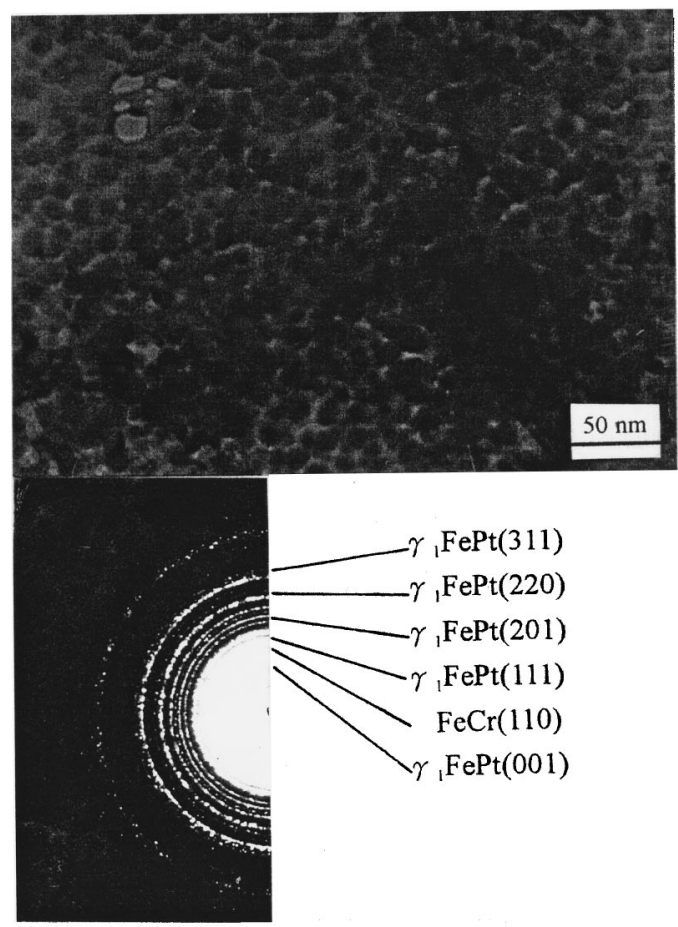

FIG. 2. TEM bright-field images and diffraction patterns of the $(\mathrm{FePt})_{95} \mathrm{Cr}_{5}$ film annealed at $650^{\circ} \mathrm{C}$ for $15 \mathrm{~min}$.

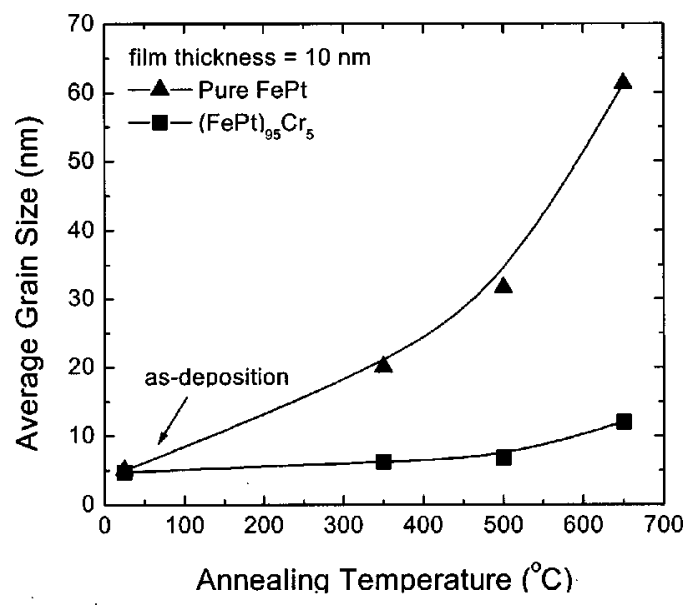

FIG. 3. Average grain size as a function of annealing temperature for the pure $\mathrm{FePt}$ and $(\mathrm{FePt})_{95} \mathrm{Cr}_{5}$ films.

were observed, however, from our experimental data, it was not sufficient to clarify the extent of $\mathrm{Cr}$ in the FePt phase.

From the observations of TEM images, Fig. 3 shows the variation of the average grain size as a function of annealing temperature $\left(T_{\text {an }}\right)$ for the pure $\mathrm{FePt}$ and $\left(\mathrm{Fe}_{50} \mathrm{Pt}_{50}\right)_{95} \mathrm{Cr}_{5}$ films. The average grain size of all the unannealed films are about the same $(\sim 5 \mathrm{~nm})$. After annealing, the average grain size of the $(\mathrm{FePt}){ }_{95} \mathrm{Cr}_{5}$ film grows slower than that of a pure FePt film. At $T_{\mathrm{an}}=650^{\circ} \mathrm{C}$, the average grain size of a pure FePt film is $60 \mathrm{~nm}$, and it is only about $12 \mathrm{~nm}$ for a $(\mathrm{FePt})_{95} \mathrm{Cr}_{5}$ film. From the TEM bright-field image and coercivity studies, we found that the effect of $\mathrm{Cr}$ addition is not only reducing the film's magnetic hardening but also limiting the grain growth of the magnetic FePt phase during annealing. Figure 4 shows the average grain size as a function of $\mathrm{Cr}$ concentration for the $(\mathrm{FePt})_{100-x} \mathrm{Cr}_{x}$ films annealed at $650^{\circ} \mathrm{C}$ for $15 \mathrm{~min}$. The average grain size decreases very fast for films containing a few percent $(<5$ at. \%) of Cr. For films containing $\mathrm{Cr}$ between 5 and 16 at. \%, they decrease slowly from 12 to $5 \mathrm{~nm}$.

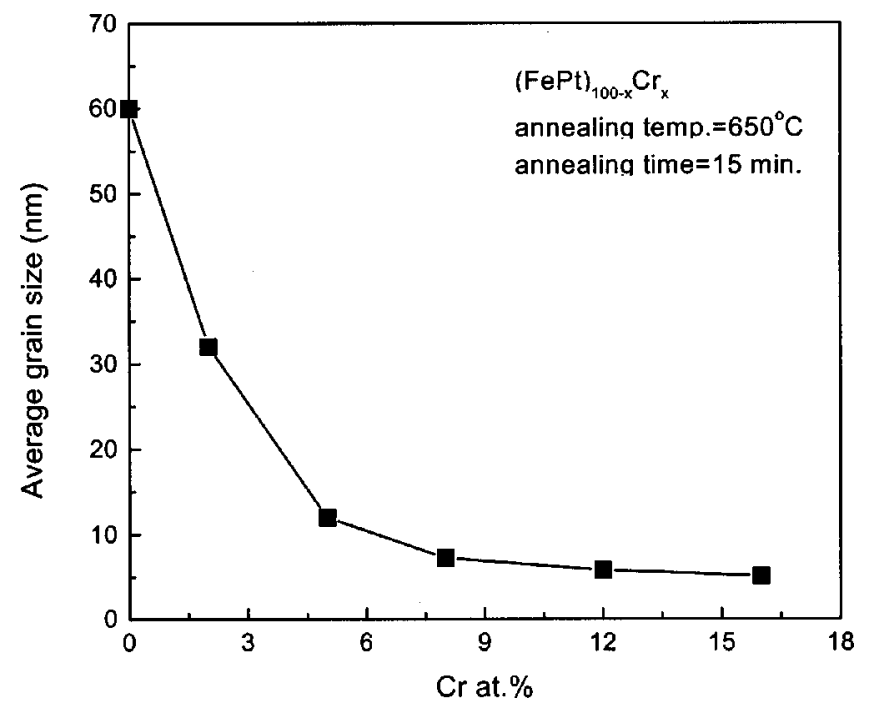

FIG. 4. Average grain size as a function of the $\mathrm{Cr}$ concentration for the $(\mathrm{FePt})_{100-x} \mathrm{Cr}_{x}$ films. 


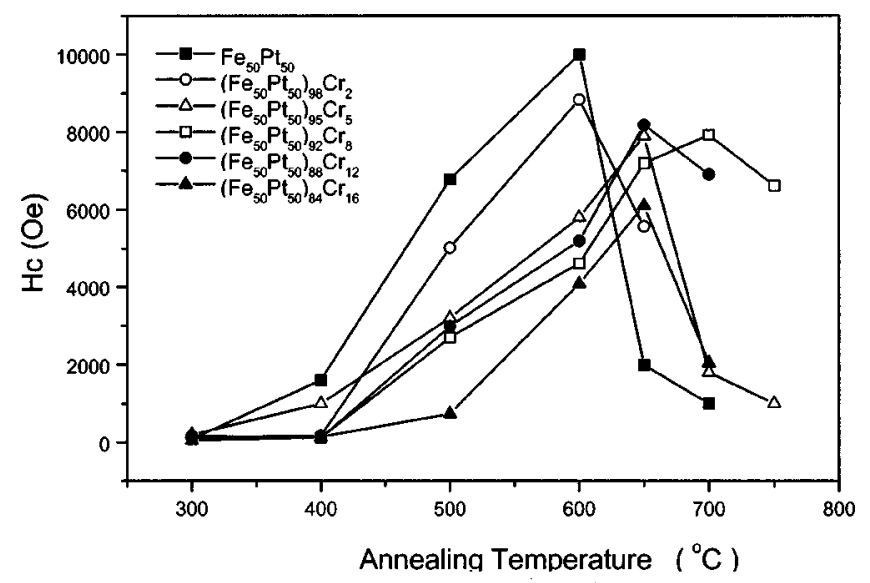

FIG. 5. Coercivity as a function of annealing temperature for the (FePt) ${ }_{100-x} \mathrm{Cr}_{x}$ alloy thin films with $x=0,2,5,8,12$, and 16 at. $\%$.

Figure 5 shows the coercivity of the $\left(\mathrm{Fe}_{50} \mathrm{Pt}_{50}\right)_{100-x} \mathrm{Cr}_{x}$ alloy thin films as a function of annealing temperatures. In general, for films annealing between 600 and $650^{\circ} \mathrm{C}$, the saturation magnetization is between 400 and $700 \mathrm{emu} / \mathrm{cm}^{3}$, and the coercivity between 4 and $10 \mathrm{kOe}$ can been achieved. The coercivity increases monotonously with the annealing temperature before reaching its maximum value. This is due to the gradual transform of the fcc $\gamma$-FePt phase to the fct
$\gamma_{1}$-FePt phase. After reaching its maximum value, the coercivity drops rapidly with increasing $T_{\mathrm{an}}$. This is due to the chemical reaction of the thin film with Si substrate.

In conclusion, we have observed that the addition of $\mathrm{Cr}$ in the FePt thin films will reduce its saturation magnetization and coercivity, however, it could inhibit the grain growth during annealing of the samples. The optimum condition for high-density magnetic recording purpose of the $(\mathrm{FePt})_{100-x} \mathrm{Cr}_{x}$ alloy films was found with $x=5$ at. $\%$, annealing at $650{ }^{\circ} \mathrm{C}$ for $15 \mathrm{~min}$, and ice water quench cooling. According to the TEM study, the average grain size in the annealed $(\mathrm{FePt})_{100-x} \mathrm{Cr}_{x}$ alloy thin films decrease from 60 to $5 \mathrm{~nm}$ with increasing $x$ from 0 to 16 .

${ }^{1}$ S. W. Yung, Y. H. Chang, T. J. Lin, and M. H. Hung, J. Magn. Magn. Mater. 116, 411 (1992).

${ }^{2}$ S. Mitani, K. Takanashi, M. Sano, H. Fujimori, A. Osawa, and H. Nakajima, J. Magn. Magn. Mater. 148, 163 (1995).

${ }^{3}$ N. Li and B. M. Lairson, IEEE Trans. Magn. 35, 1077 (1999).

${ }^{4}$ T. Suzuki, N. Honda, and K. Ouchi, J. Appl. Phys. 85, 4301 (1999).

${ }^{5}$ K. Watanabe and H. Masumoto, Trans. Jpn. Inst. Met. 24, 627 (1983).

${ }^{6} \mathrm{M}$. Watanabe, T. Nakayama, K. Watanabe, and K. Kiraga, IEEE Trans. Magn. 8, 875 (1993).

${ }^{7}$ B. Zhang and W. A. Soffa, Scr. Metall. Mater. 30, 683 (1994).

${ }^{8}$ M. Watanabe, T. Nakayama, K. Watanabe, T. Hirayama, and A. Tonomura, Mater. Trans., JIM 37, 489 (1996).

${ }^{9}$ C. M. Kuo, P. C. Kuo, and H. C. Wu, J. Appl. Phys. 85, 2264 (1999).

${ }^{10}$ C. M. Kuo, P. C. Kuo, H. C. Wu, Y. D. Yao, and C. H. Lin, J. Appl. Phys. 85, 4886 (1999). 